\section{Bronchial Thermoplasty}

\section{Ready for Prime Time - The Evidence Is There!}

\section{To the Editor:}

The challenging of previously published work and reviews of studies with a new and different perspective is rational and academically appropriate when performed with scientific rigor and accuracy. However, we were surprised by the recent commentary in CHEST (July 2014) by Iyer and $\mathrm{Lim}^{1}$ regarding bronchial thermoplasty (BT).

In questioning the evidence supporting the benefits of $\mathrm{BT}$, the authors' speculation that one patient with multiple hospitalizations drove the entire statistical difference between the groups is unfounded. The reduction in ED visits of $84 \%$ between the $\mathrm{BT}$ and sham groups ${ }^{2}$ changes to a reduction of $70 \%$ when the outlier is excluded.

Asthma severity was defined according to recognized standards at the time the Asthma Intervention Research (AIR)-2 trial was designed. Thus, in response to the authors' question, $86 \%$ of the BT group and $88 \%$ of the sham group were indeed severe per American Thoracic Society criteria for severe refractory asthma ${ }^{3}$ and had, on average, only $17 \%$ symptom-free days, further demonstrating poor asthma control.

The authors' contention that an AQLQ (Asthma Quality of Life Questionnaire) difference of 0.19 in the AIR-2 trial would not reflect any meaningful improvement in AQLQ for patients or clinicians is incorrect because a group mean change does not reflect individual patient improvement. Consistent with the validation of the AQLQ, ${ }^{4}$ the clinical meaningfulness of this difference was determined by the demonstration of more patients in the BT group (79\%) achieving the minimally important difference of 0.5 compared with the sham group (64\%) (posterior probability superiority [ppsuperiority], 99.6\%).

The authors' contention that there was no difference in severe exacerbations and time lost from work, school, and other activities related to asthma is also inaccurate. There was a $32 \%$ reduction in severe exacerbations (ppsuperiority, 95.5\%) and a 66\% reduction in days lost (ppsuperiority, 99.3\%) compared with the sham group. ${ }^{2}$ These measures were prespecified as "other" end points and were predefined in the statistical analysis plan.
The authors' statement that the benefits seen in the sham group might have been sustained after 1 year is speculative and irrelevant. Published data show that patients with asthma receiving high-intensity treatment (ie, high-dose inhaled corticosteroids and long-acting $\beta$-agonists in the index year) do not experience an improvement in exacerbations or hospitalizations due to asthma over time. ${ }^{5}$ Regardless of whether the sham subjects' asthma status was maintained, the benefit of BT in AQLQ and other end points was superior to sham at 1 year. ${ }^{2}$ Careful follow-up of $>85 \%$ of the BT group out to 5 years demonstrated that the reduction in severe exacerbations seen in year 1 was maintained with no safety concerns. ${ }^{6}$

The authors have misrepresented the US Food and Drug Administration (FDA) approval process and the FDA Modernization Act of 1997. The contention that BT was approved based on the results of a single trial is wrong. The FDA panel of independent experts examined data from four clinical trials and found the data to be compelling and meeting criteria for safety and effectiveness, leading to its recommendation that BT be approved for treating severe asthma in appropriately selected patients. For a single center's view to be published without review for accuracy, even as a commentary, is surprising and potentially damaging to efforts to bring new and effective therapy to patients.

Mario Castro, MD, MPH, FCCP

St. Louis, $M O$

Gerard Cox, MB

Toronto, ON, Canada

Michael E. Wechsler, MD, MMSC

Denver, $C O$

Robert M. Niven, MD

Manchester, England

AfFiliations: From the Division of Pulmonary and Critical Care Medicine (Dr Castro), Washington University School of Medicine; Firestone Institute of Respiratory Health (Dr Cox), St. Joseph's Healthcare; National Jewish Health (Dr Wechsler); and University of Manchester and University Hospital of South Manchester (Dr Niven). FINANCIAL/NONFINANCIAL DISCLOSURES: The authors have reported to CHEST the following conflicts of interest: Dr Castro receives university grant monies from the National Institutes of Health and American Lung Association and pharmaceutical grant monies from Amgen Inc; Boston Scientific Corporation; Ception Therapeutics, Inc and Cephalon Inc, subsidiaries of Teva Pharmaceutical Industries Ltd; Genentech, Inc; GlaxoSmithKline plc; KaloBios; MedImmune, LLC; Nexbio, Inc; Novartis AG; sanofi aventis US LLC; and Vectura Group plc. 
He receives royalties from Elsevier BV and consultant fees from Boston Scientific Corporation; Genentech, Inc; Holaira Inc; and NeoStem, Inc. Dr Castro receives speaking fees from GlaxoSmithKline plc, Genentech Inc, Boehringer Ingelheim GmbH, Boston Scientific Corporation, and Teva Pharmaceuticals Industries Ltd. He has stock options with Sparo Labs. Dr Cox has participated in clinical research trials of bronchial thermoplasty supported by Asthmatx, Inc/Boston Scientific Corporation and has received consultant and speaking fees related to bronchial thermoplasty. Dr Wechsler has received honoraria from Boston Scientific Corporation for consulting and for speaking engagements. Dr Niven has received lecture fees for international lectures from Boston Scientific Corporation over the past 3 years and has received lecture fees from or participated on the advisory boards of AstraZeneca, Boehringer Ingelheim GmbH, GlaxoSmithKline plc, Novartis Corporation, and Vectura Group plc.

CORRESPONDENCE TO: Mario Castro, MD, MPH, FCCP, Division of Pulmonary and Critical Care Medicine, Washington University School of Medicine, 660 S Euclid Ave, Campus Box 8052, St. Louis, MO 63110; e-mail: castrom@wustl.edu

(c) 2015 AMERICAN COLLEGE OF CHEST PHYSICIANS. Reproduction of this article is prohibited without written permission from the American College of Chest Physicians. See online for more details.

DOI: $10.1378 /$ chest.14-2296

\section{References}

1. Iyer VN, Lim KG. Bronchial thermoplasty: reappraising the evidence (or lack thereof). Chest. 2014;146(1):17-21.

2. Castro M, Rubin AS, Laviolette M, et al; AIR2 Trial Study Group. Effectiveness and safety of bronchial thermoplasty in the treatmen of severe asthma: a multicenter, randomized, double-blind, shamcontrolled clinical trial. Am J Respir Crit Care Med. 2010;181(2): 116-124.

3. American Thoracic Society. Proceedings of the ATS workshop on refractory asthma: current understanding, recommendations, and unanswered questions. Am J Respir Crit Care Med. 2000;162(6): 2341-2351.

4. Juniper EF, Guyatt GH, Willan A, Griffith LE. Determining a minimal important change in a disease-specific Quality of Life Questionnaire. J Clin Epidemiol. 1994;47(1):81-87.

5. Schatz M, Meckley LM, Kim M, Stockwell BT, Castro M. Asthma exacerbation rates in adults are unchanged over a 5-year period despite high-intensity therapy. J Allergy Clin Immunol Pract. 2014;2(5):570-574.

6. Wechsler ME, Laviolette M, Rubin AS, et al; Asthma Intervention Research 2 Trial Study Group. Bronchial thermoplasty: long-term safety and effectiveness in patients with severe persistent asthma. J Allergy Clin Immunol. 2013;132(6):1295-1302.

\section{Response}

\section{To the Editor:}

"res ipsa loquitur" - the thing speaks for itself

We welcome the opportunity to engage in an open and transparent discussion with Dr Castro and colleagues regarding our recent article in $C H E S T^{1}$ and the scientific merits of thermoplasty in asthma. They imply that critical appraisal of a peer-reviewed published paper requires multicenter corroboration for accuracy. We stand by our commentary on the Asthma Intervention Research (AIR)-2 trial and would like to reiterate several important facts.

The Methods section of the AIR2 trial is very clear in stating that "The primary outcome was the difference between study groups in the AQLQ (Asthma Quality of
Life Questionnaire) change from baseline to the average of the 6, 9 and 12 month scores (integrated AQLQ)."2 This stated primary end point of the AIR2 trial did not achieve statistical significance (posterior probability of superiority of $96.0 \%$ vs the prespecified cutoff value of $96.4 \%)$.

The proportion of patients in each group that achieved $\mathrm{a} \geq 0.5$ increase in AQLQ was not the primary outcome of interest. This should be considered an exploratory analysis that has little bearing on the discussion regarding efficacy of thermoplasty. Moreover, important secondary end points (percentage of symptom-free days, total symptom score, $\mathrm{FEV}_{1}$, peak expiratory flow, rescue medication use) showed absolutely no difference between the two groups.

Long-term follow-up of patients in each arm of a clinical trial is essential (and very relevant) when studying chronic diseases such as asthma, heart disease, diabetes, and so forth. ${ }^{3,4}$ The long-term efficacy of an intervention such as thermoplasty can be judged only when follow-up outcomes in the control group (sham thermoplasty) are also available. Patients in the sham thermoplasty group showed robust clinical improvement in the AIR2 trial and it behooves us to know whether they maintained their improvement without undergoing actual thermoplasty.

The AIR2 trial was not designed or powered to assess "other end points" such as emergency room visits or hospitalizations. In fact, patients with $\geq 3$ hospitalizations, steroid pulses, or lower respiratory infections/year were specifically excluded from the study. Furthermore, the small number of events (about $13 \mathrm{ED}$ visits in the bronchial thermoplasty group vs about 42 in the sham group) could have been influenced by one or more outliers, as is illustrated vividly in the hospitalization data. Release of the entire data set into the public domain will allow for further analysis of such outliers. Furthermore, relative risk reduction overstates the benefit (or harm) with small event numbers and should be interpreted very cautiously.

The US Food and Drug Administration-approved thermoplasty was based on only one double-blind randomized controlled trial. ${ }^{1}$ The other three thermoplasty trials were all unblinded studies that should not be grouped together with the AIR2 trial, given our understanding of asthma ${ }^{5}$ and the strong placebo effect of invasive procedures. ${ }^{6}$

Bronchial thermoplasty is not the first procedure that has been tried in patients with asthma, ${ }^{7}$ and it will surely not be the last. We should be satisfied by nothing but the very best in evidence and efficacy for our patients with asthma. 
Vivek N. Iyer, $M D, M P H$

Kaiser G. Lim, MD, FCCP

Rochester, MN

AfFiliations: From the Division of Pulmonary and Critical Care Medicine, Mayo Clinic.

FINANCIAL/NONFINANCIAL DISCLOSURES: The authors have reported to CHEST that no potential conflicts of interest exist with any companies/organizations whose products or services may be discussed in this article.

CORRESPONDENCE TO: Vivek N. Iyer, MD, MPH, Division of Pulmonary and Critical Care Medicine, Mayo Clinic, 200 First St SW, Rochester, MN 55905; e-mail: iyer.vivek@mayo.edu

(c) 2015 AMERICAN COLLEGE OF CHEST PHYSICIANS. Reproduction of this article is prohibited without written permission from the American College of Chest Physicians. See online for more details.

DOI: $10.1378 /$ chest.14-2456

\section{References}

1. Iyer VN, Lim KG. Bronchial thermoplasty: reappraising the evidence (or lack thereof). Chest. 2014;146(1):17-21.

2. Castro M, Cox G. Asthma outcomes from bronchial thermoplasty in the AIR2 trial. Am J Respir Crit Care Med. 2011;184(6): 743-744.

3. Patel A, MacMahon S, Chalmers J, et al; ADVANCE Collaborative Group. Intensive blood glucose control and vascular outcomes in patients with type 2 diabetes. $N$ Engl J Med. 2008;358(24): 2560-2572.

4. Zoungas S, Chalmers J, Neal B, et al; ADVANCE-ON Collaborative Group. Follow-up of blood-pressure lowering and glucose control in type 2 diabetes. N Engl J Med. 2014;371(15):1392-1406.

5. Wechsler ME, Kelley JM, Boyd IO, et al. Active albuterol or placebo, sham acupuncture, or no intervention in asthma. $N$ Engl J Med. 2011;365(2):119-126.

6. Sihvonen R, Paavola M, Malmivaara A, et al; Finnish Degenerative Meniscal Lesion Study (FIDELITY) Group. Arthroscopic partial meniscectomy versus sham surgery for a degenerative meniscal tear. N Engl J Med. 2013;369(26):2515-2524.

7. Overholt RH. Glomectomy for asthma. Dis Chest. 1961;40:605-610.

\section{Response}

\section{From the Editor:}

In their rebuttal to the Commentary on bronchial thermoplasty by Iyer and $\mathrm{Lim}^{1}$ that appeared recently in CHEST (July 2014), Dr Castro and colleagues ${ }^{2}$ state that we published the Commentary without review for accuracy. This is not true. Given the importance of the subject matter, we made sure that the manuscript underwent careful and close scrutiny before publication. ${ }^{1}$ Our reasons for going ahead with publishing the Commentary are well reflected by the response of Drs Iyer and Lim. ${ }^{3}$

Richard S. Irwin, MD, Master FCCP

Glenview, IL

AFFILIATIONS: From the Editorial Office of CHEST.

FINANCIAL/NONFINANCIAL DISCLOSURES: The author has reported to CHEST the following conflicts of interest: Dr Irwin is Editor-in-Chief of CHEST and made the final decision to publish the Commentary. CORRESPONDENCE TO: Richard S. Irwin, MD, Master FCCP, American College of Chest Physicians, 2595 Patriot Boulevard, Glenview, IL 60026; e-mail: Richard.Irwin@umassmemorial.org

(c) 2015 AMERICAN COLLEGE OF CHEST PHYSICIANS. Reproduction of this article is prohibited without written permission from the American College of Chest Physicians. See online for more details.

DOI: $10.1378 /$ chest.14-3032

\section{References}

1. Iyer VN, Lim KG. Bronchial thermoplasty: reappraising the evidence (or lack thereof). Chest. 2014;146(1):17-21.

2. Castro M, Cox G, Wechsler ME, Niven RM. Bronchial thermoplasty: ready for prime time - the evidence is there! Chest. 2015;147(2):e73-e74.

3. Iyer VN, Lim KG. Response. Chest. 2015;147(2):e74-e75. 